\title{
O ACASO, O PROVÁVEL, O DETERMINÍSTICO: COMO CONCEBEM E O QUE CONHECEM PROFESSORES DO ENSINO FUNDAMENTAL
}

\author{
CHANCE, PROBABILITY AND DETERMINISM: WHAT ELEMENTARY \\ AND MIDDLE SCHOOL TEACHERS CONCEIVE AND WHAT THEY KNOW
}

\author{
Michaelle Renata Moraes de Santana ${ }^{1}$ \\ Rute Elizabete de Souza Rosa Borba ${ }^{2}$
}

\begin{abstract}
Resumo: A formação básica em probabilidade torna-se indispensável ao cidadão nos dias de hoje e em tempos futuros, pois a sociedade contemporânea requer habilidades que permitam uma leitura ampla da realidade e capacidades de intervenção nas ações sociais e essas têm, muitas vezes, natureza probabilística. Nosso trabalho baseou-se na análise de diversos estudos, identificando as diferentes tendências quanto às noções básicas de probabilidade a serem abordadas no Ensino Fundamental. Participaram do estudo oito professores, quatro dos anos iniciais e quatro dos anos finais, que responderam ao nosso instrumento de pesquisa - uma entrevista relacionada a concepções e conhecimentos probabilísticos. Com isso, pudemos obter informações referentes aos professores, relacionando-as com suas formações iniciais. De um modo geral, pode-se afirmar que há indícios de que a formação inicial influencia na construção de concepções quanto ao ensino de probabilidade e de que se faz necessário possibilitar, durante o processo de formação de professores, discussões referentes a conhecimentos probabilísticos, de forma que os docentes adquiram autonomia para trabalhar com esse conceito, favorecendo uma aprendizagem significativa dos seus alunos.
\end{abstract}

Palavras-chave: Probabilidade; Concepções docentes; Ensino Fundamental.

\begin{abstract}
Basic learning in probability is indispensable to the citizen today and in future times, since contemporary society requires skills that allow a broad reading of reality and intervention capacities in social actions and these are often probabilistic in nature. Our research was based on the analysis of several studies, identifying the different tendencies regarding the basic notions of probability to be approached in Elementary and Middle School. Eight teachers, four of Elementary School and four of Middle school, answered our research instrument - an interview related to probabilistic conceptions and knowledge. With this, we were able to obtain information about the teachers, relating them to their initial teacher education. In general, it can be affirmed that there is evidence that initial education influences the construction of conceptions regarding the teaching of probability and that it is necessary to enable, during the teacher education process, discussions regarding probabilistic knowledge, so that teachers acquire autonomy to work with this concept, favoring a meaningful learning of their students.
\end{abstract}

Keywords: Probability; Teaching concepts; Elementary and Middle School.

\footnotetext{
${ }^{1}$ Mestre em Educação Matemática e Tecnológica pela Universidade Federal de Pernambuco (UFPE). Doutoranda em Educação Matemática e Tecnológica pela Universidade Federal de Pernambuco (UFPE), Recife, Pernambuco, Brasil. E-mail: mikarmoraes@ hotmail.com

${ }^{2} \mathrm{PhD}$ pela Oxford Brookes University. Professora da Universidade Federal de Pernambuco (UFPE), Recife, Pernambuco, Brasil. E-mail: resrborba@gmail.com
} 


\section{Introdução}

Nos dias atuais faz-se necessário que a escola estimule, desde o Ensino Fundamental, a formação de conceitos de natureza probabilística, pois para o estudante compreender o mundo que os cerca é preciso entender o que é aleatório, o que é determinístico, o que é impossível, possível e provável. Essa compreensão ampla da probabilidade pode ser obtida por intermédio de experiências que permitam aos alunos fazerem observações, levantarem conjecturas e tirarem conclusões, desenvolvendo, assim, seus pensamentos científicos, fundamental para suas formações.

Para que a aprendizagem matemática possa contribuir para a efetivação desse fato, é importante que estudantes desenvolvam procedimentos matemáticos diversos, que sejam confrontados com problemas variados do mundo real e que tenham possibilidades de escolherem suas próprias estratégias para solucioná-los. Uma possibilidade de tornar isso possível é propor em sala de aula a vivência de situações probabilísticas de naturezas diversas, como problemas, experimentos e jogos que tratam direta e indiretamente da probabilidade.

Oliveira e Cazorla (2008) afirmam que é papel da escola proporcionar ao estudante a formação de conceitos probabilísticos que o auxiliarão no exercício de sua cidadania. Esse conhecimento é necessário para o indivíduo compreender as informações veiculadas, tomar decisões e fazer previsões que influenciam na sua vida pessoal e na de sua comunidade.

Lopes (2005) defende a ideia de que a probabilidade é uma excelente oportunidade para refletir com os estudantes sobre como matematizar, como aplicar a Matemática para resolver problemas reais. Argumenta-se que para isso é preciso que o ensino das noções probabilísticas utilize uma metodologia pela qual se incentiva o aluno à descoberta, à invenção, por meio de propostas de problemas concretos e da realização de experimentos reais e/ou simulados.

Nesse sentido, ensinar conceitos probabilísticos na escola é de extrema importância, pois a relação com o mundo necessita, mais que nunca, que se distingam certezas de incertezas, contribuindo para o exercício pleno da cidadania com responsabilidade social na tomada de decisões. Sem esta compreensão, os indivíduos não são capazes de julgar de forma adequada o meio que os cerca e podem se deixar levar por informações destorcidas da realidade. 
Nessa perspectiva, na escolarização básica, os professores devem promover uma formação na qual os estudantes pensem mais amplamente a respeito de diferentes questões e estabeleçam adequadamente estratégias e técnicas para solucionar problemas que permeiam sua vida - a qual inclui situações prováveis, improváveis e impossíveis com as quais é preciso aprender a lidar. É importante que professores estejam preparados para trabalharem nos anos iniciais do Ensino Fundamental com noções probabilísticas que gradativamente serão aprofundadas nos outros níveis de escolarização.

\section{$2 \mathrm{O}$ ensino da probabilidade e a formação de professores}

Atualmente, o ensino da Matemática tem se justificado pelas necessidades dos estudantes construírem e recriarem conhecimentos, desenvolverem a imaginação e a criatividade, assim como por uma necessidade social de instrumentá-los para a vida social. Cada vez mais e mais rapidamente tem-se exigido diferenciadas habilidades e competências matemáticas dos cidadãos, pois novos elementos se fazem presentes no diaa-dia dos indivíduos.

Em relação à probabilidade, os Parâmetros Curriculares Nacionais (BRASIL, 1997), consideram que esta pode promover a compreensão de grande parte dos acontecimentos do cotidiano que são de natureza aleatória, possibilitando a identificação de resultados possíveis desses acontecimentos. Afirma-se, ainda, que as noções de acaso e incerteza, que se manifestam intuitivamente, podem ser exploradas na escola, em situações nas quais o aluno realiza experimentos e observa eventos (em espaços equiprováveis) (BRASIL, 1997, p.57).

Piaget e Inhelder (1951) realizaram uma investigação sobre a capacidade de crianças compararem probabilidades e identificaram três estágios no raciocínio probabilístico de crianças. No primeiro estágio, as crianças utilizam critérios subjetivos na comparação de probabilidades, pois elas ainda não desenvolveram as estruturas das operações lógicas elementares. O segundo estágio é caracterizado por uma construção de grupos numéricos, mas sobre um plano essencialmente concreto. No terceiro estágio, por fim, diante de um conjunto de problemas envolvendo probabilidades, ocorre uma solução geral e rápida. Para esses autores, o conceito de probabilidade é construído gradualmente em cada indivíduo, mas só é formado plenamente na adolescência. Consideramos, aqui, que este conhecimento é construído na interação entre maturidade e aprendizagem 
escolar, cabendo, então, à escola esse papel primordial no desenvolvimento da compreensão da probabilidade.

Segundo Oliveira \& Cazorla (2008), em geral, os professores que lecionam Matemática a crianças e adolescentes não foram preparados, nos cursos de formação inicial, para ensinar conteúdos como a probabilidade. Afirmam, ainda, que são escassos os materiais didáticos que apresentam as noções de probabilidade de modo adequado para a Educação Básica, e os livros didáticos, em geral, o fazem de maneira descontextualizada e fragmentada, sem motivar o aluno para a aprendizagem da probabilidade.

Como afirma Coutinho (2005), se faz necessária uma formação docente específica para o trabalho com o aleatório, com enfoque experimental para a introdução ao conceito de probabilidade. Dessa forma, se possibilitará que o professor adquira autonomia para formular e executar uma organização matemática e didática desse conteúdo, visando a Escola Básica.

Para Lopes (1998), faz-se necessário desenvolver uma prática pedagógica na qual sejam propostas situações em que os estudantes realizem atividades, observando e construindo os eventos possíveis, através de experimentação concreta. A aprendizagem da probabilidade só complementará a formação dos alunos se for significativa, se considerar situações familiares a eles, situações que sejam contextualizadas, investigadas e analisadas.

Segundo esta autora, a opção por essa abordagem de ensino e aprendizagem deveria iniciar-se nos primeiros anos de escolaridade para que as crianças possam vivenciá-las, desde suas primeiras descobertas, não fazendo sentido trabalhar atividades envolvendo conceitos probabilísticos que não sejam vinculados a uma problemática. Assim, acreditamos que é preciso iniciar cedo a problematização crítica e reflexiva com a probabilidade, a partir de atividades que possam levar o estudante a repensar seu modo de ver o mundo em que se encontra inserido.

Portanto, o ensino da probabilidade inicialmente deve ser realizado através de experimentações, observações, registros, coletas e análises de dados de modo interdisciplinar, possibilitando aos estudantes a compreensão que a incerteza e a imprevisibilidade se fazem presentes no cotidiano das pessoas, contribuindo, assim, em seu processo de apreensão e ação na realidade. Desta forma, o professor deve entender o ensino da probabilidade como construção de conceitos que devem estar articulados ao contexto sociocultural do estudante e norteados pela formação de um cidadão autônomo. 
Assim, consideramos relevante possibilitar ao estudante o trabalho com probabilidade, e para tanto, é essencial que professores concebam a importância de trabalhar esse conceito e que tenham conhecimento dos aspectos básicos da probabilidade a serem ensinados.

\subsection{O que apontam algumas pesquisas anteriores em probabilidade}

O levantamento de estudos anteriores sobre a probabilidade pode auxiliar na compreensão de como este conceito se desenvolve, bem como no planejamento e acompanhamento de processos de ensino e aprendizagem de conceitos probabilísticos.

Coutinho (2003) apresentou uma análise dos Parâmetros Curriculares Nacionais, a partir da construção de uma adaptação da sequência didática proposta em Coutinho (2001), permitindo perceber o papel do ensino da probabilidade na formação do estudante do ensino fundamental brasileiro. A autora destaca que a construção do conceito de probabilidade pelos alunos é feita a partir da compreensão de três noções básicas: percepção do acaso, ideia de experiência aleatória e a noção de probabilidade. Nesse sentido, Coutinho (2003) propõe a construção de uma rede de conhecimentos que favorecerá o aluno, ao término do Ensino Fundamental, reconhecer situações aleatórias, identificar resultados possíveis e estimar a probabilidade de alguns desses resultados.

Lopes (2004) apresentou uma análise sobre o ensino da probabilidade e da estatística dentro do currículo de Matemática na Escola Básica. Nesse estudo, os focos da discussão foram as recomendações curriculares de Matemática para a escola básica e a metodologia da resolução de problemas para o desenvolvimento do pensamento estocástico $^{3}$. Como principal resultado obtido por Lopes (2004), tem-se que o trabalho em sala de aula deve ocorrer através da resolução de problemas, exigindo, portanto, a necessidade de alteração sobre a concepção de estatística e probabilidade no currículo de formação inicial e continuada dos professores da escola básica.

Gonçalves (2004), em sua dissertação de mestrado, realizou um estudo com o objetivo de identificar as concepções de professores de Matemática em exercício no Ensino Fundamental sobre probabilidade, verificando se há relação entre o que os professores de Matemática construíram quando alunos do ensino básico com as suas concepções atuais sobre aleatoriedade e probabilidade. A partir dos dados coletados,

\footnotetext{
${ }^{3}$ Refere-se ao modelo de pensamento que possibilita ao sujeito perceber a possibilidade de um fato aleatório ocorrer.
} 
através do instrumento diagnóstico, Gonçalves (2004) concluiu que há indícios de que a prática docente influencia na mudança de concepções, pois na amostra foi possível observar que professores que obtiveram sua formação básica no mesmo período e atuam em anos ou níveis distintos possuem concepções também distintas.

Muniz e Gonçalves (2005), em estudo realizado com professores que ensinam Matemática no Ensino Fundamental, buscaram analisar quais construções e processos são identificados em suas práxis em relação ao ensino de noções estocásticas na escola. Para atingir os objetivos propostos no estudo, os autores vivenciaram, inicialmente, o cotidiano de uma professora de $4^{\mathrm{a}}$ série (atual $5^{\circ}$ ano) de uma escola pública municipal, buscando conhecer a realidade do ensino da Matemática, dando ênfase à presença de conceitos estocásticos no contexto da sala de aula. Em um segundo momento, foi oferecido um curso de extensão para professores, discutindo, com base na realidade deles, o ensino de noções estocásticas, objetivando perceber suas construções diante desses conteúdos.

Assim, na pesquisa, foram apresentados pelos professores obstáculos de natureza epistemológica e didática em suas práxis pedagógicas. Os autores consideraram que os professores sentem-se despreparados para o ensino de noções estocásticas, devido às dificuldades encontradas na elaboração desses conceitos que exigem construção reflexiva sobre a ideia de acaso e aleatoriedade.

Coutinho (2007), no estudo intitulado Conceitos probabilísticos: quais contextos a história aponta?, discutiu o papel da história do conceito de probabilidade na escolha de contextos para a apresentação dos primeiros conceitos probabilísticos no Ensino Fundamental, visando propiciar ao professor uma diversidade de contextos possíveis e de apreensões probabilísticas para o trabalho com a ideia de acaso e as noções de probabilidade e de modelo probabilista, sob o ponto de vista de sua gênese histórica. A autora focaliza a existência de um tipo de dualidade para a apreensão da noção de probabilidade, devida à coexistência dos enfoques laplaciano e frequentista. Nesse sentido, mostra-se fundamental a identificação do contexto no qual o acaso é identificado para que se possa construir o significado do valor de probabilidade atribuído ao evento em estudo.

No estudo realizado por Novaes e Coutinho (2009) as autoras discutem sobre as primeiras noções de probabilidade. Afirmam que em nosso cotidiano estamos cercados de fenômenos que são devidos ao acaso, nos levando a tomar decisões. As autoras exemplificam como, no lançamento de uma moeda, sabe-se que a face voltada para cima pode ser cara ou coroa, mas não se será cara na primeira jogada. Pode-se, ainda, 
reproduzir esse experimento tantas vezes quantas se desejar, sempre nas mesmas condições, ainda que mentalmente. Nesse caso, não se podem calcular esses resultados com precisão, mas pode-se determinar o grau de incerteza na sua ocorrência ao qual chamamos de probabilidade.

Bryant e Nunes (2012), realizaram levantamento de estudos sobre como se compreende a probabilidade. O relatório, publicado pela Fundação Nuffield de Oxford, aponta que são exigidas quatro demandas cognitivas para a compreensão da probabilidade: entendimento da aleatoriedade, saber identificar o espaço amostral, essencial para resolver qualquer problema de probabilidade, comparar e quantificar probabilidades, de forma que realize comparações de dois ou mais eventos e estabelecer correlação ou relação entre eventos.

Felisberto de Carvalho (2017) investigou como um programa formativo favorece a construção dos conhecimentos didático-matemáticos sobre probabilidade com professores de Matemática dos anos finais do Ensino Fundamental. O processo formativo foi vivenciado com 40 professores durante sete encontros, envolvendo uma adaptação das sequências de atividades propostas no programa de ensino de Bryant e Nunes (2012) e atividades que complementassem as reflexões sobre probabilidade e seu ensino. Um dos resultados apontados por Felisberto de Carvalho (2017) é que os conhecimentos iniciais que demonstraram ter o grupo de professores participantes, sobre probabilidade e seu ensino, são insuficientes para um processo de ensino e aprendizagem idôneo com os alunos do Ensino Fundamental.

\section{0 percurso metodológico do estudo}

Participaram da pesquisa oito professores do Ensino Fundamental de escolas públicas, sendo quatro dos anos iniciais e quatro dos anos finais. Tivemos por finalidade realizar o levantamento, a partir de entrevistas com situações-problema, de concepções e conhecimentos sobre a probabilidade, especificamente as noções que os professores consideram serem necessárias na construção desse conceito.

Realizamos uma entrevista semi-estruturada com os professores investigados na qual foram apresentadas algumas situações-problema envolvendo a probabilidade. Estas situações-problema foram selecionadas a partir da análise de alguns livros didáticos aprovados no Plano Nacional do Livro Didático 2007 (BRASIL, 2006) e analisados em estudo anterior por Santana e Borba (2010), considerando as noções abordadas pelos 
autores ao explorarem o conteúdo de Probabilidade. Sendo assim, as situações-problema selecionadas para o instrumento de pesquisa envolveram diferentes noções, como as de chance, possibilidades e probabilidade.

Inicialmente, foi realizada uma aproximação com cada participante através de um questionário que caracterizava cada um deles e, em seguida, aplicou-se o instrumento (entrevista com situações-problema que envolviam a probabilidade). As situações eram, inicialmente, apresentadas ao professor uma de cada vez e era dado um tempo para ele ler, analisar e posteriormente comentar sobre a mesma. Em alguns momentos, eram apresentadas mais de uma situação juntas para que o professor pudesse realizar uma análise das semelhanças e diferenças entre as questões.

\section{Resultados encontrados na pesquisa}

\subsection{Formação e atuação profissional dos participantes}

Os participantes do estudo eram professores do Ensino Fundamental de escolas distintas, cujas características se encontram no Quadro 1.

\begin{tabular}{|c|c|c|c|}
\hline & Formação Acadêmica & $\begin{array}{c}\text { Tempo de experiência de } \\
\text { ensino }\end{array}$ & $\begin{array}{l}\text { Ano(s) que } \\
\text { leciona }\end{array}$ \\
\hline P1 & $\begin{array}{c}\text { Pedagogia } \\
\text { Especialização em Psicopedagogia }\end{array}$ & 10 anos & $5^{\circ}$ \\
\hline $\mathbf{P 2}$ & $\begin{array}{l}\text { Pedagogia } \\
\text { Especialização em Formação de } \\
\text { Educadores }\end{array}$ & 07 anos & $5^{\circ}$ \\
\hline $\mathbf{P 3}$ & $\begin{array}{c}\text { Pedagogia } \\
\text { Especialização em Gestão Educacional }\end{array}$ & 17 anos & $5^{\circ}$ \\
\hline $\mathbf{P 4}$ & Pedagogia & 25 anos & $4^{\circ}$ e $5^{\circ}$ \\
\hline P5 & $\begin{array}{c}\text { Licenciatura em Matemática } \\
\text { Especialização no Ensino da Matemática }\end{array}$ & 02 anos & $6^{\circ}$ ao $9^{\circ}$ \\
\hline P6 & $\begin{array}{c}\text { Licenciatura em Matemática } \\
\text { Especialização em Matemática } \\
\text { Financeira }\end{array}$ & 06 anos & $7^{\circ}$ ao $9^{\circ}$ \\
\hline P7 & $\begin{array}{c}\text { Licenciatura em Matemática } \\
\text { Especialização no Ensino da Matemática }\end{array}$ & 27 anos & $6^{\circ}$ e $7^{\circ}$ \\
\hline P8 & Licenciatura em Matemática & 05 anos & $6^{\circ}$ ao $9^{\circ}$ \\
\hline
\end{tabular}

Quadro 1: Perfil profissional dos Participantes da Pesquisa Fonte: SANTANA (2011)

Observamos no grupo entrevistado que todos os participantes possuem graduação nas suas respectivas áreas de atuação. Verificamos, ainda, que seis professores possuem 
pós-graduações latu sensu em cursos diversos e que somente dois dos participantes, P4 e P8 possuem apenas graduação. Destacamos, também, que as instituições de graduação dos participantes são diversas, indicando diferentes possibilidades de formação inicial e apenas P3 e P4 não tiveram experiência de estudo em instituições públicas.

Em relação ao tempo de experiência de ensino, os professores possuem mais de cinco anos em sala de aula com exceção de P5 que lecionava apenas há dois anos. Além disso, os professores P4 e P7 apresentam mais de 20 anos de experiência, aspecto esse que pode ser um diferenciador no discurso desses professores.

Outro elemento observado foi que os professores com formação acadêmica em Pedagogia atuam em turmas dos anos iniciais do Ensino Fundamental, mais especificamente no $4^{\circ}$ e $5^{\circ}$ ano, turmas nas quais são introduzidos conceitos relacionados ao nosso objeto de estudo, o ensino de probabilidade.

Os participantes também foram questionados sobre a participação em encontros/cursos de formação continuada, pois buscávamos entender se esses professores tinham tido a oportunidade de aperfeiçoar suas competências profissionais. Foi possível identificar, por meio dos dados levantados, que há uma preocupação com a formação em serviço, tanto por parte dos profissionais, que buscam participar desses momentos, como também por parte das instituições que promovem a formação continuada aos seus profissionais. Todos os professores afirmaram ter participado de momentos de formação continuada oferecidos pela rede de ensino que atuam. No entanto, professores que lecionam nos anos iniciais do Ensino Fundamental enfatizaram que nenhuma das formações oferecidas era específica para a disciplina de Matemática.

\subsection{Investigando o conhecimento sobre probabilidade}

Iniciamos a entrevista solicitando aos participantes da pesquisa que informassem os conceitos matemáticos trabalhados nas turmas que eles lecionavam e apenas P2 incluiu a probabilidade nos conteúdos descritos. Isso indica que, espontaneamente, apenas um professor destacou a probabilidade como conceito rotineiramente trabalhado. Nenhum dos outros professores mencionou, inicialmente, esse conceito.

Na sequência, apresentamos aos professores nove situações-problema nas quais, uma a uma, íamos solicitando que eles identificassem que conceitos matemáticos estavam envolvidos nas situações. 
Primeiramente, apresentamos as situações S1, S2 e S3, com o objetivo de verificar se os professores consideravam que nestas situações explorava-se o conteúdo de probabilidade. Ao analisar as situações, os professores P1, P2, P3 descreveram diversos conceitos matemáticos, tais como operações, classificação, agrupamento, grandezas e medidas e geometria.

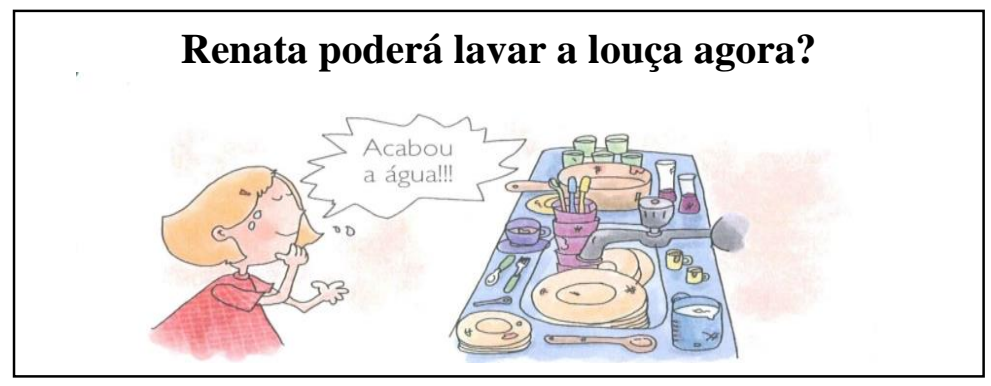

Situação $1^{4}$

Objetivos: Nessa situação esperávamos que os participantes percebessem que existem situações do cotidiano nas quais não existe a ação do acaso. Conforme a situação acima, não é possível lavar a louça, pois acabou a água na torneira.

Ao analisar a Situação 1 apenas P1, P2 e P5 consideram que a partir da situação pode-se explorar conceitos relacionados a probabilidade e possibilidades.

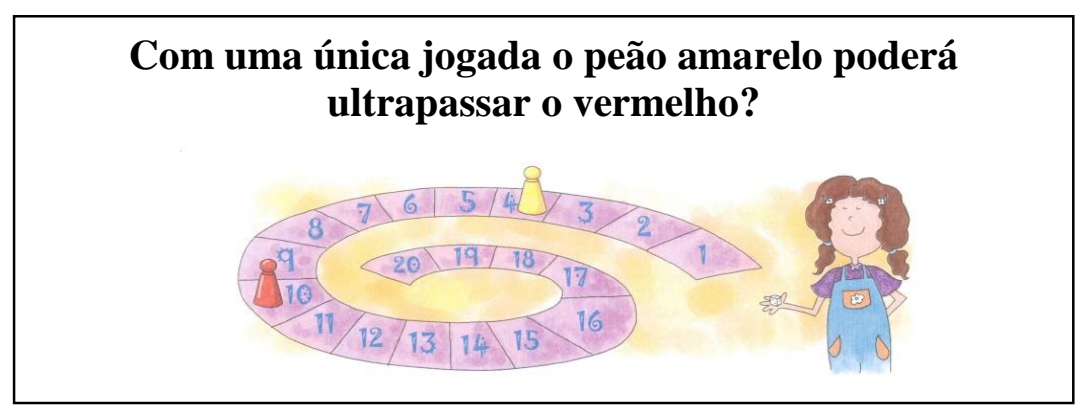

Situação $2^{5}$

Objetivos: Ao apresentar a Situação 2 esperávamos que os professores entrevistados percebessem a noção de chance. Dessa forma, seria necessário observar que ao jogar um dado de seis faces, com uma única jogada, o peão amarelo não teria chance de ultrapassar o peão vermelho pois o mesmo se encontra seis casas a frente do peão amarelo e o jogador, ao lançar o dado, mesmo obtendo um número seis não conseguiria

\footnotetext{
${ }^{4}$ Atividade selecionada do livro: BUENO, A; LEITE, A; TAVARES, S. Coleção Pensar e Viver - $4^{\mathrm{a}}$ série - 2. ed. São Paulo: Editora Ática, 2004.

${ }^{5}$ Atividade selecionada do livro: BUENO, A; LEITE, A; TAVARES, S. Coleção Pensar e Viver $-4^{\mathrm{a}}$ série - 2. ed. São Paulo: Editora Ática, 2004.
} 
sair à frente, pois o máximo que ele alcançaria era chegar na mesma casa que o peão vermelho se encontra.

Na Situação 2, a maioria dos participantes (P2, P3, P5, P7 e P8) citou a probabilidade como possível de ser explorada na situação- problema. O participante P5 ainda destacou que a porcentagem é um conteúdo que encontra-se associado à probabilidade.

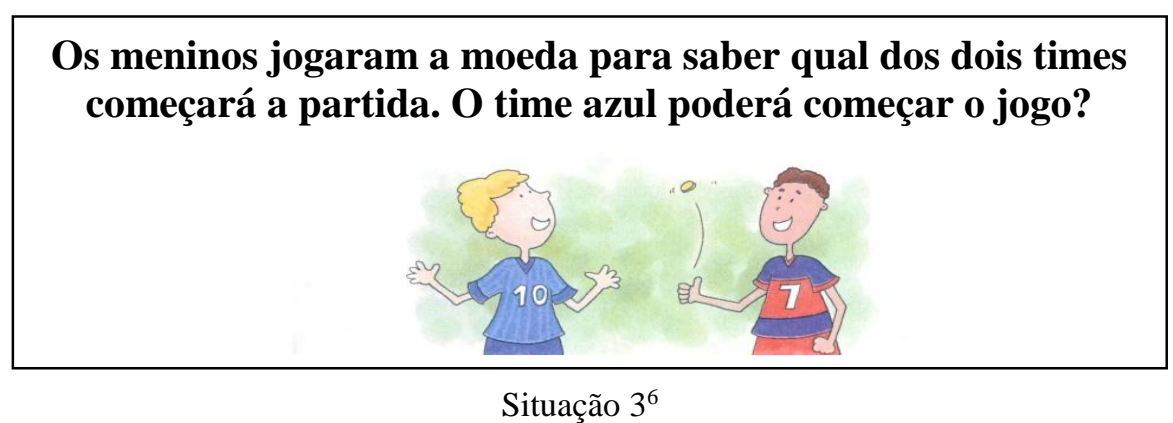

Objetivos: Na Situação 3 esperávamos que os professores percebessem que no cotidiano estamos sempre cercados de fenômenos que são devidos ao acaso, como por exemplo, um sorteio de cara ou coroa para determinar quem tem a posse de bola no início de um jogo de futebol. Observamos, também, que essa situação trata do número total de possibilidades. Nota-se que nessa situação o número de possibilidades não está explícito.

Ao analisarem a Situação 3, todos os participantes afirmaram que a situação explora o conceito de probabilidade. Observamos ainda, na fala de alguns participantes, a presença de noções básicas como chance, possibilidade e probabilidade expressa em porcentagem.

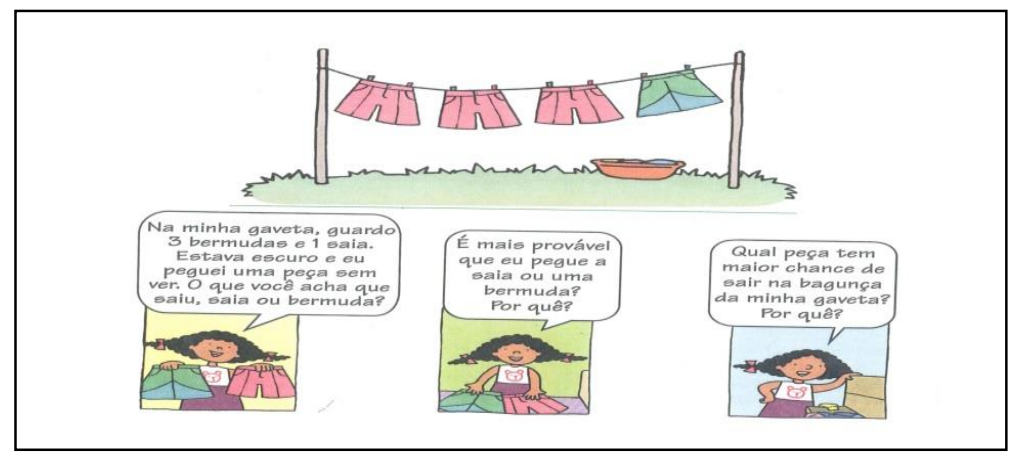

Situação $4^{7}$

\footnotetext{
${ }^{6}$ Atividade selecionada do livro: BUENO, A; LEITE, A; TAVARES, S. Coleção Pensar e Viver $-4{ }^{\mathrm{a}}$ série - 2. ed. São Paulo: Editora Ática, 2004.

${ }^{7}$ Atividade selecionada do livro: NETTO, S e PANOSSIAN, M. Coleção Um passo de cada vez $-4^{\mathrm{a}}$ série - São Paulo: Editora Escala Educacional, 2005.
} 
Objetivos: Na Situação 4 esperávamos que os professores percebessem que a noção de probabilidade envolvida seria a noção de chance. Além disso, a discussão sobre o que é mais provável, ou menos provável pode vir auxiliar a listagem de possibilidades. Nota-se também que nessa situação a própria representação auxilia a listagem das possibilidades por explicitar esse número.

Na Situação 4, grande parte dos participantes (P1, P2, P4, P5, P7 e P8) identificaram a probabilidade na situação-problema. Observamos que alguns participantes (P1, P3 e P6) associaram a situação-problema ao conceito de combinatória por se tratar de um contexto de roupas. Observamos que os participantes consideravam que a situação abordava o conceito de probabilidade, porém não explicitaram a noção de chance envolvida na Situação 4.

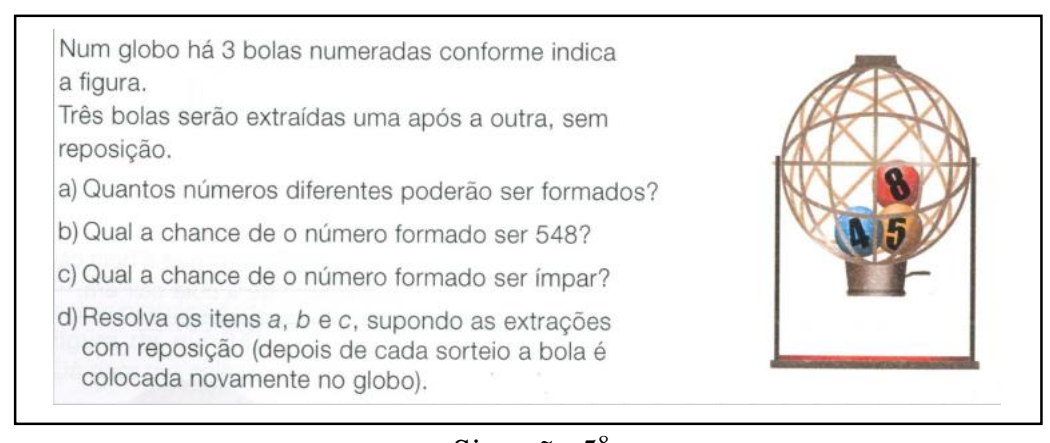

Situação $5^{8}$

Objetivos: A Situação 5 também envolve a noção de chance, no entanto difere da Situação 4 no que diz respeito à questão do contexto, pois a Situação 4 trata de roupas e a Situação 5 já explora a questão de bolas num globo. Outro ponto que difere é que a Situação 5 exige um pouco mais na sua resolução, pois além de não haver a explicitação das possibilidades, ainda solicita a descrição dos resultados quando há reposição das bolas.

Mais uma vez, ao analisarem a Situação 5, a maioria dos participantes (P1, P2, P5, P7 e P8) identificaram a probabilidade na situação-problema. Evidenciaram também a noção de probabilidade expressa em fração e a probabilidade expressa em porcentagem, conforme afirmou P4.

\footnotetext{
${ }^{8}$ Atividade selecionada do livro: BONLORNO, J.; BONJORNO, R. e OLIVARES, A. Coleção Fazendo a Diferença - $8^{\mathrm{a}}$ série - São Paulo: Editora FTD, 2006.
} 


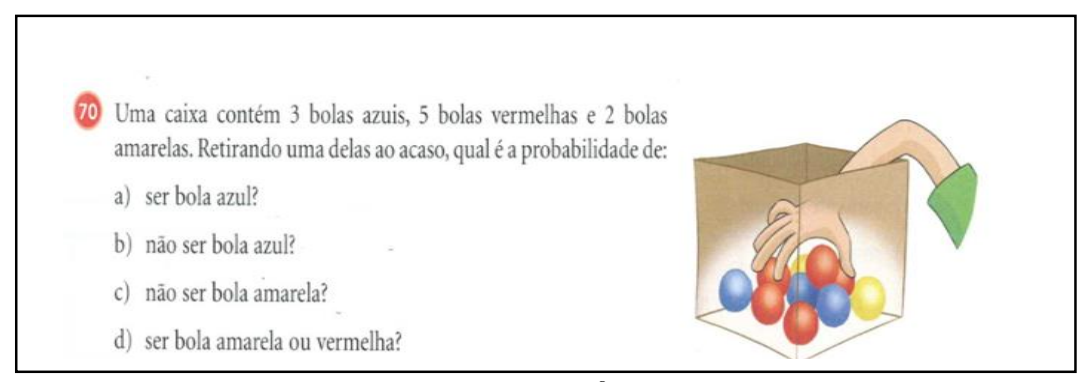

Situação $6^{9}$

Objetivos: Nessa situação esperávamos que os participantes identificassem a noção de probabilidade como a própria questão já explicita em seu enunciado e que evidenciassem a noção de acaso também.

Na Situação 6, a noção de probabilidade está expressa no enunciado da própria situação o que levou a todos os participantes identificarem a probabilidade na situaçãoproblema, no entanto evidenciaram também a noção de acaso, conforme afirmou P5.

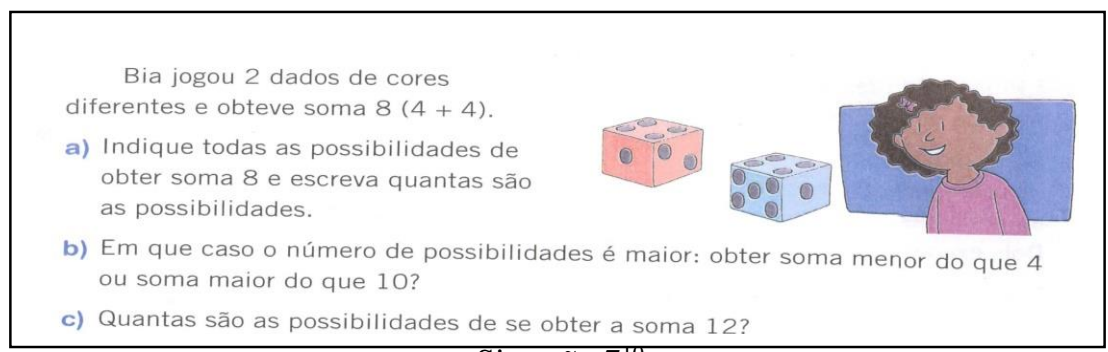

Situação $7^{10}$

Objetivos: Na Situação 7 esperávamos que os participantes evidenciassem a noção de possibilidades, assim como a construção da definição de espaço amostral. Essa situação permite a discussão sobre essa definição, pois exige a descrição da relação de alguns dos casos possíveis.

Na Situação 7, seis dos participantes (P1, P2, P3, P4, P7 e P8) identificam a probabilidade na situação-problema.

Nas situações-problema 8 e 9 os participantes destacaram que além da probabilidade as situações envolviam outro conceito matemático, no caso a porcentagem, e, após a análise dessas duas últimas situações, informaram que nas situações vistas anteriormente poderiam explorar também o conceito de porcentagem.

\footnotetext{
${ }^{9}$ Atividade selecionada do livro: DANTE, L. Tudo é Matemática $-8^{\mathrm{a}}$ série - São Paulo: Editora Ática, 2005.

${ }^{10}$ Atividade selecionada do livro: DANTE, L. Coleção Aprendendo Sempre $-5^{\circ}$ ano - São Paulo: Editora Ática, 2008.
} 


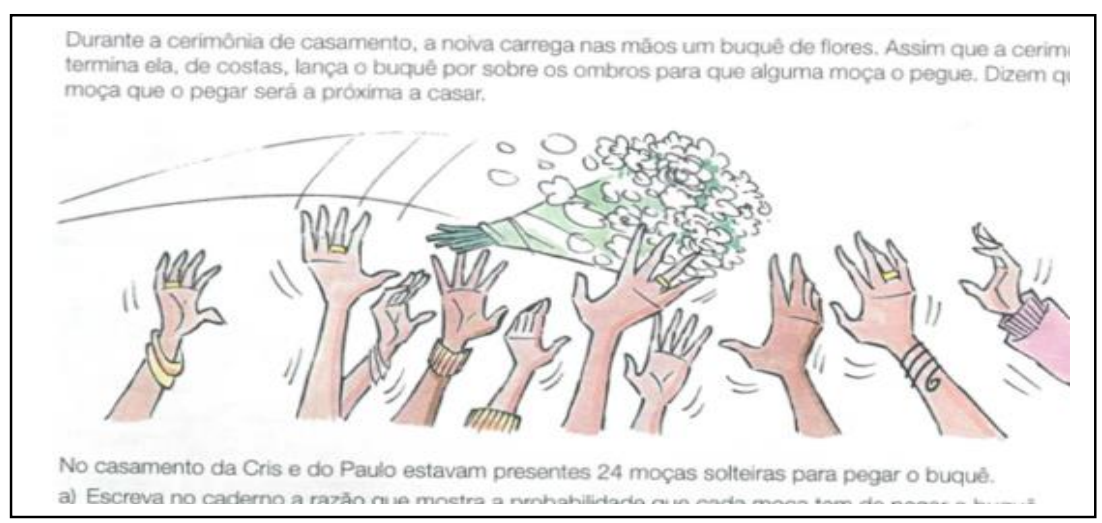

Situação $8^{11}$

Objetivos: Nessa Situação 8 tínhamos como objetivo que os participantes identificassem a noção de probabilidade expressa em razão e em porcentagem.

Ao analisarem a Situação 8, os participantes evidenciam a porcentagem e a probabilidade como conceitos abordados na situação-problema por ficar expresso no enunciado da questão.

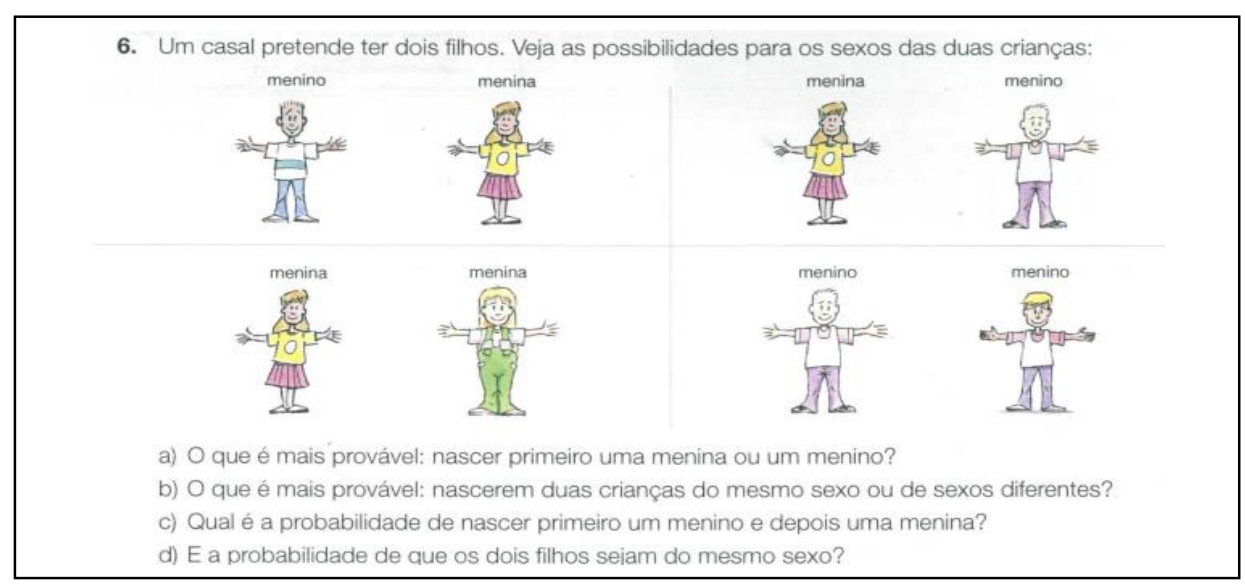

Situação $9^{12}$

Objetivos: Nessa Situação 9 os objetivos eram levar os professores a observarem os eventos mais prováveis e a noção de probabilidade expressa em porcentagem, a partir da comparação de probabilidade.

Nessa situação (Situação 9), os participantes evidenciaram a porcentagem e a probabilidade como conceitos abordados na situação-problema. Associaram, ainda, a descrição das possibilidades, conforme apresenta a situação, à Combinatória .

\footnotetext{
${ }^{11}$ Atividade selecionada do livro: SPINELLI, W. e SOUZA, M. Coleção Matemática - $6^{\mathrm{a}}$ série - São Paulo: Editora Ática, 2005.

${ }^{12}$ Atividade selecionada do livro: SPINELLI, W. e SOUZA, M. Coleção Matemática- $6^{\text {a }}$ série - São Paulo: Editora Ática, 2005.
} 
Após esse momento, propomos aos participantes que eles realizassem uma análise comparativa das situações apresentadas anteriormente, identificando algumas diferenças ou semelhanças entre as mesmas. Iniciamos retomando a Situação 4 e a Situação 5, com o objetivo de que os professores percebessem que as duas situações exploravam a noção de chance, no entanto, se diferenciavam no contexto apresentado. A seguir um quadro síntese da análise dos participantes.

\begin{tabular}{|l|l|l|}
\hline Professor & Semelhanças entre Situação 4 e Situação 5 & Diferenças entre Situação 4 e Situação 5 \\
\hline P1 & Combinação e Probabilidade & Contexto \\
\hline P2 & Possibilidades, Chance & Contexto \\
\hline P3 & Probabilidade & Valor posicional dos números \\
\hline P4 & Chance, Probabilidade & Nenhuma \\
\hline P5 & Chance & Contexto \\
\hline P6 & Combinação & Contexto \\
\hline P7 & Possibilidade, Comparação, Probabilidade & Contexto \\
\hline P8 & Probabilidade, chance & Contexto \\
\hline
\end{tabular}

Quadro 2: Síntese de comparativo entre a Situação 4 e Situação 5

Fonte: SANTANA (2011)

Apenas quatro professores, P2, P4, P5 e P8 identificaram que as duas situações se assemelhavam, pois exploravam a noção de chance. Com relação às diferenças, com exceção de P3 e P4, todos os professores concordaram que as situações se diferenciavam no contexto.

Podemos constatar a partir do Quadro 02 que professores dos anos iniciais apontaram a probabilidade como principal semelhança entre as situações. Em relação às diferenças apontadas destacamos o professor P3 quando pontuou que na Situação 5, poderia abordar a noção de quadro valor e lugar, a partir da possibilidade de formar centenas com os algarismos propostos, diferentemente da Situação 4.

Posteriormente, retomamos a Situação 6 e a Situação 7 para que eles também realizassem comparações. Nosso objetivo era que os professores percebessem que as situações se diferenciavam no contexto e nas noções exploradas, já que a Situação 6 aborda a noção de probabilidade e a Situação 7 explora a noção de possibilidades. A seguir um quadro síntese da análise dos participantes.

\begin{tabular}{|l|l|l|}
\hline Professor & Semelhanças entre Situação 6 e Situação 7 & Diferenças entre Situação 6 e Situação 7 \\
\hline P1 & Possibilidade, Probabilidade & Contexto \\
\hline P2 & Possibilidades & Contexto \\
\hline P3 & Noção de quantidade & Contexto \\
\hline
\end{tabular}




\begin{tabular}{|l|l|l|}
\hline P4 & Probabilidade, Estimativa & Contexto \\
\hline P5 & Nenhuma & Possibilidade e probabilidade \\
\hline P6 & Forma de resolução & Nenhuma \\
\hline P7 & Possibilidades & Contexto \\
\hline P8 & Possibilidades & Contexto \\
\hline
\end{tabular}

Quadro 3: Síntese de comparativo entre a Situação 6 e Situação 7

Fonte: SANTANA(2011)

Na comparação entre as Situações 6 e 7, apenas um participante, P5, identificou que as situações se diferenciavam tanto no contexto como nas noções exploradas, tendo em vista, que uma abordava a noção de possibilidade e a outra de probabilidade. Outro aspecto que podemos observar a partir do Quadro 03: a dificuldade de diferenciação das noções de possibilidade e probabilidade a partir das semelhanças identificadas tanto pelos professores dos anos iniciais, como dos anos finais.

E por fim, solicitamos que retomassem a Situação 8 e a Situação 9 para também realizar comparações. Nosso objetivo era que os professores percebessem que as situações se diferenciavam no contexto e se assemelham na noção de probabilidade. A seguir um quadro síntese da análise dos participantes.

\begin{tabular}{|l|l|l|}
\hline Professor & Semelhanças entre Situação 8 e Situação 9 & Diferenças entre Situação 8 e Situação 9 \\
\hline P1 & Probabilidade & Porcentagem \\
\hline P2 & Possibilidades & Grau de complexidade \\
\hline P3 & Possibilidade e probabilidade & Contexto \\
\hline P4 & Probabilidade & Razão e contexto \\
\hline P5 & Probabilidade & Razão e porcentagem \\
\hline P6 & Possibilidade & Contexto \\
\hline P7 & Possibilidade, probabilidade & Nenhuma \\
\hline P8 & Nenhuma & Porcentagem \\
\hline
\end{tabular}

Quadro 4: Síntese de comparativo entre a Situação 8 e Situação 9

Fonte: SANTANA(2011)

Ao realizarem a análise comparativa entre as situações 8 e 9, apenas os participantes P2, P6 e P8 não identificaram a noção de probabilidade presente em ambas as situações. 
Observamos, a partir do Quadro 04, que os professores P1, P5 e P8 apresentaram como diferenças entre as situações o conceito de porcentagem. Nesse caso, salientamos que a Situação 8 solicita a probabilidade em forma de porcentagem explicitamente, enquanto que a Situação 9 deixa a critério de quem vai resolvê-la a maneira de representar a probabilidade, ou seja, pode abordar a porcentagem de maneira implícita.

Os professores P4 e P5 apontaram como diferença entre as situações a abordagem do conceito de razão, isso pode ter se evidenciado tendo em vista que no enunciado da Situação 8 solicita-se que seja descrita a razão que representa a probabilidade do evento.

Perguntamos, ainda, aos professores entrevistados quais das situações os seus alunos resolveriam com maior facilidade ou dificuldade. No quadro abaixo podemos observar como os professores classificaram as situações em termos de grau de complexidade na resolução pelos alunos.

\begin{tabular}{|l|l|l|}
\hline Professor & $\begin{array}{l}\text { Situações mais fáceis dos alunos } \\
\text { resolverem }\end{array}$ & $\begin{array}{l}\text { Situações mais difíceis dos alunos } \\
\text { resolverem }\end{array}$ \\
\hline P1 & S1, S2, S7 e S4 & S3, S5, S6, S9, S8 \\
\hline P2 & S2, S7, S3 & S6 e S8 \\
\hline P3 & S2, S3, S4, S5, S6 e S7 & S1, S8 e S9 \\
\hline P4 & S2 e S6 & S3 e S8 \\
\hline P5 & S1, S2, S3 e S4 & S5, S6, S7, S8 e S9 \\
\hline P6 & S1, S2, S3, S4 e S7 & S5, S6, S8 e S9 \\
\hline P7 & S1, S2, S3, S4 e S7 & S5, S7, S8 e S9 \\
\hline P8 & S1, S2, S3, S4 & S5, S6, S7, S8 e S9 \\
\hline
\end{tabular}

Quadro 5: Classificação das situações pelo grau de complexidade

Fonte: SANTANA(2011)

A partir do Quadro 5 os professores dos anos iniciais indicaram como situações de maior facilidade as situações S2 e S7 e a de maior dificuldade a Situação 8. Nesse caso, a dificuldade dessa situação se justifica aparentemente por solicitar a probabilidade em forma de porcentagem, o que necessita de uma divisão inexata.

Os professores dos anos finais consideraram como mais fáceis as situações $\mathrm{S} 1$, $\mathrm{S} 2, \mathrm{~S} 3$ e S4 e como mais difíceis as situações $\mathrm{S} 5, \mathrm{~S} 8$ e S9. O que podemos verificar é que os professores, de uma forma geral, avaliaram as primeiras situações como sendo mais fáceis de resolver, pois a forma como essas situações são apresentadas, com desenhos e com contextos próximos da realidade dos alunos, ajudam na compreensão e resolução por parte dos mesmos. 
Por fim, perguntamos se eles consideram o ensino da probabilidade importante para a formação do aluno e todos os participantes enfatizaram ser muito importante e necessária a aprendizagem desse conceito, porém ressaltaram que é pouco explorado. Eles argumentaram que a probabilidade está presente nas situações diárias do aluno e que ele precisa compreender esse conceito matemático.

\section{Conclusões}

Nossa pesquisa teve como objetivo identificar, as concepções e conhecimentos que professores do Ensino Fundamental consideram necessários na construção do conceito de probabilidade.

A partir do que foi observado, pode-se concluir que, ao menos para estes participantes, professores do Ensino Fundamental exploram muito pouco os conceitos probabilísticos em suas salas de aula, justificando que os livros didáticos utilizados não oferecem subsídios para se trabalhar com esse conteúdo. Os docentes declaram também que durante suas formações iniciais não foram oferecidos elementos formativos que incorporassem saberes e práticas que permitissem o desenvolvimento de abordagens educativas que orientasse o ensino das noções básicas de probabilidade em sala de aula, como evidenciado em Oliveira \& Cazorla (2008).

Constatou-se, ainda, que professores dos anos iniciais abordam o conteúdo de probabilidade fazendo uma relação com as técnicas de contagem, limitando-se a situações de jogos, ou escolhas de uma entre várias possibilidades de resultados de uma contagem.

Observamos também que os professores dos dois níveis de escolarização apresentam conhecimentos de algumas das noções de probabilidade. No entanto, parecem ter concepções de ensino da probabilidade diferenciadas, tendo em vista que os professores dos anos finais são especialistas (diplomados em Licenciatura em Matemática) que segundo Coutinho (2003), acarreta em uma formação matemática mais aprofundada, porém, isso não garante uma concepção padronizada, se entendermos como concepção uma interiorização do saber e uma forma de mobilização própria a cada indivíduo.

Acreditamos que seja necessária a realização na escola de um trabalho mais aprofundado envolvendo conceitos probabilísticos, desde os anos iniciais, que favoreça a construção do conceito de probabilidade a partir de noções básicas, tais como: percepção do acaso, ideia de experiência aleatória e a noção de probabilidade, conforme propõe 
Coutinho (2001). Para isso, porém, se faz necessário proporcionar ao professor, durante o seu processo de formação, discussões referentes ao ensino de probabilidade, de forma que esse professor adquira autonomia para trabalhar com esse conceito e favoreça uma aprendizagem significativa dos seus alunos.

\section{Referências}

BRASIL. Guia do livro didático 2007: Matemática: séries/anos iniciais do ensino fundamental/ Secretaria de Educação Básica. Brasília: Ministério da Educação, Secretaria de Educação Básica, 2006.

BRASIL. Ministério da Educação. Secretaria de Educação Fundamental. Parâmetros Curriculares Nacionais: Matemática. ( $1^{\circ}$ e $2^{\circ}$ ciclos do ensino fundamental). v.3. Brasília: MEC, 1997.

BRYANT, P.; Nunes, T. Children's understanding of probability: a literature review. Nuffield Foundation, 2012.

COUTINHO, C. Introduction aux situations aléatoires dès le Collège: de la modélisation à la simulation d'expériences de Bernoulli dans l'environnement informatique Cabri-géomètre II. 2001. 338f. Tese (Doutorado em Matemática) - Grenoble Université Joseph Fourier, França, 2001.

COUTINHO, C. Modelagem, simulação e as orientações dos PCN-EF para o ensino de probabilidade. In: SEMINÁRIO IASI DE ESTATÍSTICA APLICADA, 9, 2003, Rio de Janeiro. Anais... Rio de Janeiro, 2003. s. p.

COUTINHO, C. A percepção da aleatoriedade e o ensino de probabilidades: um projeto para formação continuada de professores. In:CONGRESSO IBERO-AMERICANO DE EDUCAÇÃO MATEMÁTICA, 5. 2005, Porto. Anais... Porto, 2005. p. 1-15.

COUTINHO, C. Conceitos probabilísticos: quais contextos a história nos aponta? Revemat, Florianópolis, v. 2, s.n., p. 50-67, 2007.

FELISBERTO DE CARVALHO, J. I. Um estudo sobre os conhecimentos didáticosmatemáticos de probabilidade com professores de matemática dos anos finais do Ensino Fundamental. 2017. 347f. Tese (Doutorado em Educação Matemática) - Universidade Anhanguera de São Paulo, São Paulo, 2017.

GONÇALVES, M. C. Concepções de professores e o ensino de probabilidade na escola básica. 2004. 95f. Dissertação (Mestrado em Educação Matemática) - Pontifícia Universidade Católica de São Paulo, São Paulo, 2004.

LOPES, C. A probabilidade e a estatística no ensino fundamental: uma análise curricular. 1998. Dissertação (Mestrado em Educação) - Universidade Estadual de Campinas, Campinas, 1998.

LOPES, C. O ensino de probabilidade e estatística na escola básica nas dimensões do currículo e da prática pedagógica. In: SIMPOSIO IBEROAMERICANO DE ENSEÑANZA

MATEMÁTICA, 16, 2004, Castelló. Anais... Castelló: Universitat Jaume I, 2004. s.p. 
LOPES, C. O desenvolvimento da Probabilidade e da Estatística. In: ENCONTRO REGIONAL DE PROFESSORES DE MATEMÁTICA, 18. 2005, Campinas. Anais... Campinas: UNICAMP, 2005. s.p.

MUNIZ, C. A.; GONÇALVES, H. J. L. A educação estatística no ensino fundamental: discussões sobre a práxis de professoras que ensinam matemática no interior de Goiás. Educação Matemática em Revista, São Paulo, v. 18/19, n.12, v.18/19, p. 26-34, 2005.

NOVAES, D; COUTINHO, C. Estatística para a educação profissional. São Paulo: Atlas, 2009.

OLIVEIRA, S.; CAZORLA, I. Ensinando probabilidades no ensino fundamental. Educação Matemática em Revista, São Paulo, v. 24, n.13, v.24, p. 3-6, 2008.

PIAGET, J.; INHELDER, B. La genése de l'idée de hasard chez l'enfant. Madrid, 1951. SANTANA, M.; BORBA, R. Como a Probabilidade tem sido abordada nos livros didáticos de Matemática de anos iniciais de escolarização. In: ENCONTRO NACIONAL DE EDUCAÇÃO MATEMÁTICA, 10, 2010, Salvador. Anais... Salvador, 2010. s.p.

SANTANA, M. O acaso, o provável, o determinístico: concepções e conhecimentos probabilísticos de professores do Ensino Fundamental. 2011.96f. Dissertação (Mestrado em Educação Matemática) - Universidade Federal de Pernambuco, Recife, 2011.

Recebido em: 20 de novembro de 2017.

Aceito em: 17 de dezembro de 2017. 